Grau, D., Cruz-Rios, F., and Sherman, R. (2019). "Project Validation - A Novel Pactice to Improve Value and Project Performance." In: Proc. 27th Annual Conference of the International. Group for Lean Construction (IGLC), Pasquire C. and Hamzeh F.R. (ed.), Dublin, Ireland, pp. 63-72. DOI: https://doi.org/10.24928/2019/0199. Available at: 〈www.iglc.net>.

\title{
PROJECT VALIDATION - A NOVEL PRACTICE TO IMPROVE VALUE AND PROJECT PERFORMANCE
}

\author{
David Grau ${ }^{1}$, Fernanda Cruz-Rios ${ }^{2}$, and Rachael Sherman ${ }^{3}$
}

\begin{abstract}
The study presented in this article investigates the practice of validation, which is not supported by the current literature. In this study, data was collected from subject matter experts through phone interviews. A multiple case study method was leveraged to characterize validation through the analysis of empirical data from remarkable project validation efforts. Project validation aims at proving or disproving with limited or no design whether the team can deliver a project that satisfies the owner's business case and scope within the owner's allowable constraints of cost and schedule and with an acceptable level of risk. During validation, multidisciplinary innovation clusters within the team investigate, compare, and propose distinct options for major project components, and enable the team to collaboratively select an option for the conceptual estimate without committing to the design of such option. Exploring solutions with a multidisciplinary lens without committing to their design enables the team, later on during design, to make decisions on solutions that ensure the cumulative impact of such solutions and further increase value to the owner. Validation culminates in a go/no-go decision, is undertaken following the business case and precedes the contractual agreement, and must have a dedicated budget, schedule, and project team. This article characterizes what validation is, when it is performed, how it should be implemented, and its benefits. Lessons learned are also discussed. When properly implemented, subject matter experts express that validation virtually eliminates cost and schedule deviations.
\end{abstract}

\section{KEYWORDS}

Value, lean construction, collaboration.

1 David Grau, Assistant Professor, School of Sustainable Engineering and the Built Environment, Arizona State University, 660 S College Avenue, Tempe, AZ 85281, USA, Phone +1 (480) 727-0665; email: david.grau@asu.edu

2 Fernand Cruz-Rios, Post-Doctoral Researcher, School of Sustainable Engineering and the Built Environment, Arizona State University, 660 S College Avenue, Tempe, AZ 85281, USA, Phone +1 (480) 727-0665; email: fernanda.cr.ford@ gmail.com

3 Rachael Sherman, Ph.D. Student, School of Sustainable Engineering and the Built Environment, Arizona State University, 660 S College Avenue, Tempe, AZ 85281, USA, Phone +1 (480) 727-0665; email: rpsherm1@asu.edu 


\section{INTRODUCTION}

Many industry leaders claim the inability of project teams to predict project performance outcomes reliably (Grau and Back 2015). Evaluation of project team performance is often based on the deviations of outcomes at completion based on initial prediction values. Implicit to such team evaluation is the assumption that deviations will occur. Predictability of cost and schedule outcomes has been low since the emergence of the modern construction industry. A "hockey stick" pattern in which the disclosure of accurate outcomes is only made late in project execution when corrective actions are difficult, expensive, or unfeasible has been norm (Grau and Back 2015). Indeed, the existence of major deviations in the delivery of capital investments has been constant since early in the $20^{\text {th }}$ century (Flyvbjerg 2006). Thus, the eradication of cost and schedule deviations would become a major cornerstone for the construction industry.

In reality, the capability to reliably predict time and cost outcomes at completion early, as opposed to late, in the project delivery process is critical for owner and contractor organizations in an industry characterized by recurring cost and schedule deviations (Payne 1995; Flyvbjerg et al. 2002; Isidore and Back 2002; Bordat et al. 2004; McKenna et al. 2006; Liu et al., 2013; Kim and Reinschmidt 2011; Orberlender and Trost 2001; Grau et al. 2014). The weight of such deviations is often "not only by a few percent but by several factors" (Flyvbjerg 2006). An average of almost 30\% cost overrun characterized the delivery of infrastructure investments in the United Kingdom between 1927 and 1998 (Flyvbjerg 2006). No pattern of improvement relative to cost deviations existed during the seven decades of analysis. Studies based on recent project performance efforts have emphasized the persistence of such deviations. Thus, the analysis of nearly 1,000 projects completed until 2011 found that nearly $70 \%$ of them resulted in cost and schedule deviations above 10\% (Mulva and Dai 2012). Only 5\% of those projects were completed with cost and schedule deviations below 3\%. In another example, the analysis of 135 projects completed between 2008 and 2012 determined median cost and schedule deviations of $6 \%$ and $8 \%$ respectively. In Norway, substantial increments in cost estimates have been recently publicized during the front end planning of the project or even before the project is authorized (Welde and Odeck 2017). At the same time, though, the same group of researchers alerts of cost underestimation during the same front end planning phase (Andersen et al. 2016). These researchers state "the underestimation of costs at the front-end is grossly neglected in the literature compared with whether costs comply with the budget. While cost overruns are an indication of failure in terms of the project's tactical performance, the contention is that the up-front underestimation of costs might result in an inferior project being selected and thus affect the strategic performance of the project". This industry-wide uncertainty around cost and schedule performance emerges from multiple and likely intertwined causes (Back and Grau 2013a; Back and Grau 2013b). However, human behavior components have been statistically determined to result in a prevalent impact on inaccurate or biased predictions and thus largely influence predictability (Grau et al. 2016; Grau et al. 2017).

The validation of a project before making a commitment to design and construction offers the possibility to increase value to the owner and also becomes a potential solution to alleviate these endemic cost and schedule deviations. However, to date, the literature on 
project validation is null with only a recent study that tangentially addresses the practice of validation. Within an IPD-centered study, Cheng et al. (2018) documented that validation is about establishing certainty for the owner and the team whether the team can deliver a project that meets the owner constraints. In a concise discussion, the cited IPD Guide briefly discusses the reasons to validate a project, how to plan for such validation effort, and a cyclic design-estimation-constructability process to gain certainty. Building on top of these basic definitions, this study aims at providing an in-depth characterization of project validation. While most of the findings from this study support the core but succinct discussion by Cheng et al. (2018), in this study industry evidence strongly indicates that the value of validation resides in providing an answer to whether or not a project should be designed and built with no design or, at most, minimal schematic design information. Improving certainty by advancing design is not a novel competency. The rest of this article details its objectives and scope, research methodology, and results before reaching the conclusions of this study.

\section{OBJECTIVES AND SCOPE}

As a departure from previous efforts, the study presented in this article aimed at characterizing the novel practice of validation. The study focused on exploring: concepts and fundamental aspects of validation; leading-edge case studies; and lessons learned. Questions that this study aimed at explaining include: what is validation, and what it is not?; what are the resources required to perform validation?; what is a typical validation schedule and budget?; what are the necessary team skills?; what are its steps?; what are its deliverables?; what happens during the solicitation for project authorization?; or, what are the potential outcomes from such solicitation?

The scope of the study is reduced to projects that had been validated. As the results indicated, validation is primarily used in projects delivered with an Integrated Project Delivery (IPD) approach due to their same team-sharing and collaborative approach, and thus the study focused on IPD projects.

\section{METHODOLOGY}

A multiple case study method (Yin 2014) was leveraged to obtain the results from the collected data. The analysis of multiple sources of empirical evidence enables a holistic understanding of the topic of investigation (Gummesson 2000), which in this study was deemed necessary due to the lack of literature about validation. The multiple case study method also induces the emergence of core characteristics and immanent patterns of such type of novel or undocumented processes (Hartley 1994). Finally, the multiple case study analysis is best suited to document and respond to questions related to how a process, such as validation, occurs (Yin 2014). Initially, this study aimed at maximizing the number of industry experts participating in the study. A cohort of 30 potential participants from distinct organizations was individually screened with the purpose to ascertain whether their professional experiences related to project validation. Such screening was necessary due to the perceived confusion about validation among industry practitioners. As it turned out, all but eight (8) of the corresponding screened processes related to established practices 
such as business case development, front end planning, stage-gate design, or did not aim at deciding whether or not to proceed with a project.

Thus, in this study data was collected from eight subject matter experts through phone interviews with an open-ended interview protocol. Experts averaged 19 years of design and construction experience and 10.5 years of lean construction experience. Experts were affiliated with owner, designer, and contractor organizations with a record of validation efforts. Phone interviews lasted between 1 and 2 hours and were audio-recorded. During the interviews, each expert was requested to select one remarkable project validation effort as a result, for example, of scale, cost, schedule, complexity, or success. Within the context of such a project, each expert shared validation aspects such as information inputs and outputs, team and culture, validation steps, or approval solicitation. Table 1 illustrates the descriptive statistics of the sample of projects. In addition, experts were requested to shared lessons learned gained through their cumulative validation experience. After each interview, additional questions and information were communicated via email. Interview transcripts and additional information were analyzed. The rest of this article summarizes the results that characterize project validation. A comprehensive discussion of the results from the study presented in this article can be found in Grau and Cruz-Rios (2019).

Table 1. Project Sample - Descriptive Statistics

\begin{aligned} & \hline Investment Source $\begin{array}{l}\text { Private }=8 \\ \text { Public }=\text { None }\end{array} \\ &$\hline Project Sector $\begin{array}{l}\text { Healthcare }=6 \\ \text { Manufacturing }=1 \\ \end{array} \\ &$ Biotechnology $=1 \\ &$\hline Experts' Affiliation Owner $=5 \\ &$ Design and Construction $=3 \\ &$\hline Total Installed Costs (TIC) Average $=\$ 183.8$ million \\ & \hline Completion Time Average $=36.3$ months \\ & \hline Validation Costs $(\%$ of TIC) Average $=0.54 \% \\ &$\hline Validation Schedule Average $=16.9$ weeks \\ & \hline\end{aligned}

\section{WHAT IS VALIDATION?}

Project validation aims at proving or disproving with limited or no design whether the team can deliver a project that satisfies the owner's business case and scope within the owner's allowable constraints of cost and schedule and with an acceptable level of risk. During validation, multidisciplinary innovation clusters within the team investigate, compare, and propose distinct options for major project components, and enable the team to collaboratively select an option for the conceptual estimate without committing to the design of such option. Exploring solutions with a multidisciplinary lens without committing to their design enables the team, later on during design, to make decisions on solutions that ensure the cumulative impact of such solutions and further increase value to the owner. Validation culminates in an informed decision by the owner on whether to authorize (go) or not (no-go) the project and thus ahead of the final resolution to fund, 
design, and build the project. Validation is executed within a short duration and limited budget.

During the study, it came to our attention the convoluted understanding of validation among industry practitioners. We found instances of practitioners claiming the validation of their project while they were doing what they had always done and "called it something else" (quoted from one of the subject matter experts interviewed in this study). Thus, an effort was made to characterize validation. Among other intrinsic characteristics, a validation effort must unequivocally result in a go or no-go decision on behalf of the project. Also, dedicated budget and schedule resources are necessary to support the validation effort. We documented instances of validation attempts that, without such support, were obviated by project players (e.g. contractor, designers, consultants). In reality, validation requires the full-time dedication of the project team. Team members, either individually or in combination, must provide in-depth cost estimating skills (inclusive of conceptual estimating) and at least basic design skills for each discipline within the team. Finally, design is purposely kept at a minimum during validation. Schematic design is obviated or at least minimized in favor of the basis of design. The practice of validation, when properly implemented, results in an accurate cost estimate despite design drawings and specifications are not available.

\section{WHEN TO PERFORM VALIDATION?}

Validation follows the owner's business case and precedes the contractual agreement to deliver the project through design and construction. Traditionally, the need to mitigate risks and gain project knowledge before the project is authorized has required the advancement of design and corresponding estimates, which is often referred to as stage-gate design. In contrast, validation aims at an informed authorization decision with limited or no design on whether the team can meet the owner constraints. On the one hand, the owner's business case defines the owner priorities such as scope and program/operational needs that guide validation. On the other hand, validation precedes and informs schematic design, so that design only starts once validation is completed and the project has been authorized. See Figure 1. In specific instances, though, the owner requires the team to advance schematic design during validation. For example, schematic design can be performed in order to reduce completion time when an expectation exists that the project will be authorized. See Figure 2.

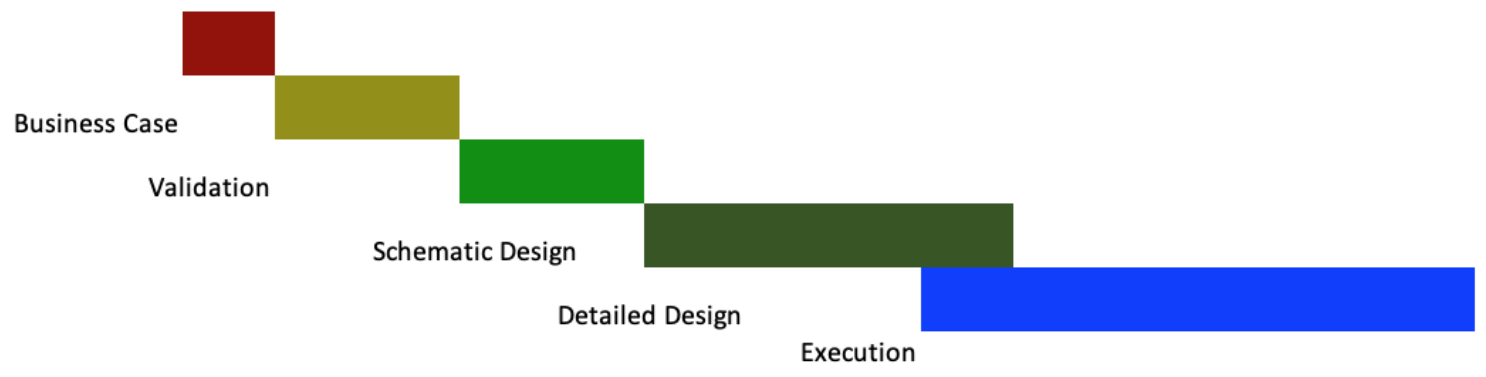


Figure 1. Validation in the Project Delivery

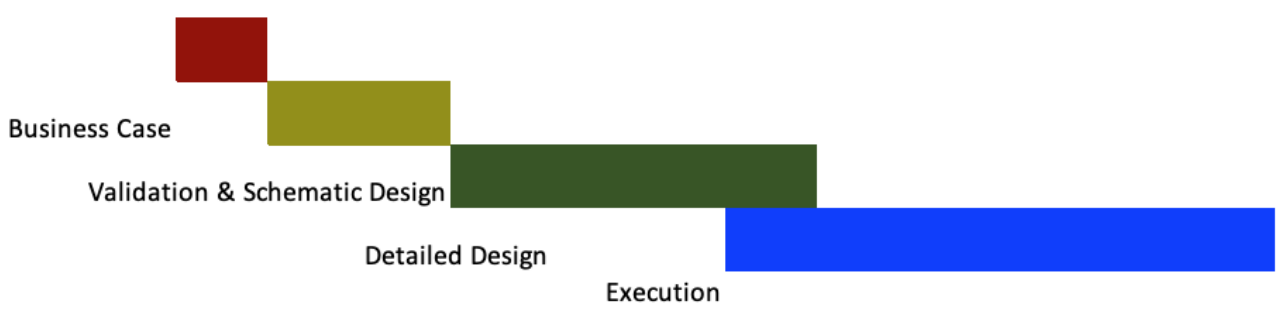

Figure 2. Concurrent Validation and Schematic Design

\section{HOW TO PERFORM VALIDATION?}

At the core of validation, a cycle of big room charrettes and cluster work events rapidly builds predictability and generates a basis of design, which, later on, will improve project value. Figure 3 illustrates the validation process, in which the subject matter experts participating in this study consistently agreed on. Big room charrettes precede cluster work and contribute to validation through multiple attributes. For instance, the team builds alignment during the face-to-face big room charrettes. Team members often meet for multiple days during every charrette and review the team objectives, project information, team behavior and conduct rules, or contrast validation progress against the initial validation milestones and thus ascertain corrective actions when necessary. During charrettes, each cluster or discipline provides an update on work status, estimates, and solicits input and feedback from the other disciplines in order to advance the estimate. In the big room, decisions are collaborative and often made in real-time. For example, A3s are created with multidisciplinary design options for the same project component so that comparisons and decisions can be efficiently made. Recording the decision-making process enables that, later on, designers can come back to such records and make informed design decisions or revise such decisions. During charrettes, the team defines the objectives for the next charrette meeting, so that multidisciplinary clusters within the team can precisely figure out the work that they must accomplish. Thus, during cluster work, multidisciplinary teams work remotely, but the team maintains a constant communication. The lapse of time between big room charrettes varies, but teams often decide to alternate charrettes and cluster work weekly, so that charrettes occur every other week and cluster work fills the week in-between charrettes. Such cycles of big room charrettes and cluster work rapidly advance the estimate, increase value, and build confidence.

When properly implemented, subject matter experts express that validation virtually eliminates cost and schedule overruns. Experts expressed that validation does not only offer the opportunity to eliminate cost overruns virtually, but also results in a pattern of reduced costs over time among similar type of projects. For example, an owner organization with a record of validation expertise set the end of validation to the attainment of a certain percentage of reduction from the allowable budget. However, the reader should notice that quantitative data to substantiate such repeated experts' claim could not be obtained. 


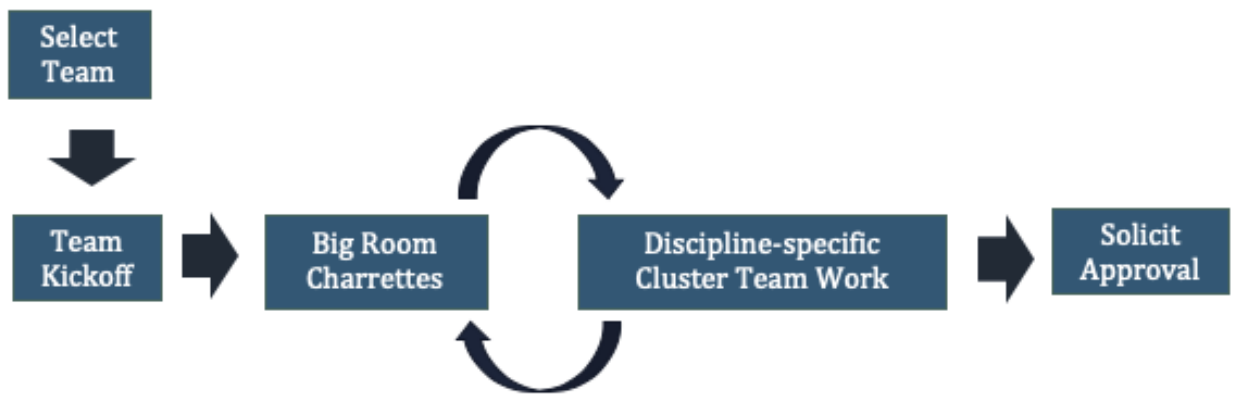

Figure 3. Validation Process

In addition, experts express that validation enhances value to the owner. During validation, the team focuses on project components and systems that can have an impact on the conceptual estimate. The team analyses and documents distinct multidisciplinary options for each major components (for instance through A3 analyses) and chooses an option in order to build the conceptual estimate without making a commitment to design and build such option. Such multidisciplinary and explorative focus drives value and innovation. In addition, exploring solutions with a multidisciplinary lens without committing to their design enables the team to, later on during design, make decisions on solutions that ensure the cumulative impact of such solutions and further increase value to the owner. Also, designers express that information loops during design are substantially reduced since the team has documented major design options.

\section{GO/NO-GO DECISION}

The outcome of validation is a report that summarizes the work of the team and becomes the basis of the presentation to the owner during approval solicitation. The validation report unequivocally determines the team commitment towards scope, schedule, and budget and provides information that supports such commitment. If the project is authorized, the validation report continuously guides design and execution.

At approval solicitation, the validation report is presented to the distinct stakeholders within the owner organization with the objective to obtain the project authorization. The owner evaluates the team commitment and the certainty that the team can meet such a commitment. Approval solicitation culminates in two possible outcomes: go or no-go.

On the one hand, that the project is authorized implies that the owner is satisfied with the team's commitment to execute an agreed-upon scope and level of risk. The project is eventually designed, built, commissioned, started, and operated. The team and the owner agree to the target cost value in the contractual agreement based on the results from project validation.

On the other hand, that the project is not authorized implies that owner priorities cannot be met or that uncertainty is too high from the owner's perspective. For example, that the project cannot be delivered to satisfy product-to-market constraints is an example of a failed priority that often leads to the cancelation of the project. However, a no-go decision does not necessarily imply that the project is forgotten -being this one possibility. Other possibilities exist. For instance, the owner may decide to reduce the project scope with the 
goal to reduce its allowable budget. Alternatively, the owner can maintain the scope and decide to freeze the project with the expectation that the allowable budget can be increased in the future. In other instances validation is extended to reduce uncertainty further before the project can be solicited for approval once more.

\section{LESSONS LEARNED}

The study presented in this article collected lessons learned, which, when implemented, enhance the chances of successful validation. Such lessons learned are introduced below.

- Conceptual estimating, the ability to estimate project costs with minimal or none design documents, is a core competency in order to eliminate schematic design during validation while still producing a reliable estimate.

- The more the maturity and experience with validation, the larger the threshold of uncertainty that the team is willing to accept when committing to the project and thus the shorter the validation process.

- An effective validation process does not necessarily add time to the total project delivery schedule since it often results in the minimization of design re-work and information loops.

- Validation most often precedes an Integrated Form of Agreement (IFOA) within the Integrated Project Delivery (IPD) approach, even though it can be eventually implemented with other delivery methods.

- When a political aspect exists, the owner should make sure to plan for and be able to manage it during validation.

\section{CONCLUSIONS}

This article presents the first research effort solely dedicated to documenting the practice of project validation. Validation proves or disproves whether the project team can successfully deliver a project while meeting the owner constraints and with an acceptable level of risk. It results in an informed decision by the owner on whether or not to authorize the project. Validation is executed with little or no design and ahead of the contractual agreement. In essence, the practice of validation generates value to the owner and builds predictability -the team's ability to anticipate project outcomes early in the delivery process. It offers owners what likely is the "biggest bang for the buck" in today's capital delivery landscape. The value of validation resides in making an informed decision (whatever the decision is) on behalf of the owner and team. Organizations with an expert validation capability regard it as a competitive advantage. Future research efforts should further advance the knowledge about validation. An understanding of how validation can be applied in projects with non-IPD delivery approaches should be investigated. Specifically, how non team-driven validation efforts can realistically build certainty and increase predictability should be answered. 


\section{ACKNOWLEDGMENTS}

We want to acknowledge and thank the Lean Construction Institute (LCI) for the sponsorship and support to all aspects of the study reported in this article. In addition, we also want to thank all the subject matter experts that contributed to this research effort through the data collection, analysis, and validation steps. Finally, we want to thank the members of the Research Committee at LCI.

\section{REFERENCES}

Andersen, B., Samset, K., and Welde, M. (2016) "Low estimates - high stakes: underestimation of costs at the front-end of projects." International Journal of Managing Projects in Business, Vol. 9 Issue: 1, pp.171-193.

Back, E., and Grau, D. (2013a). "Improving the Predictability of Project Outcomes." Construction Industry Institute, Research Summary 291-1.

Back, E., and Grau, D. (2013b). "Four-Casting for Early Predictability." Construction Industry Institute, Implementation Resource 91-2.

Bordat, C., McCullouch, B.G., Sinha, K.C., and Labi, S. (2004). "An analysis of cost overruns and time delays of INDOT projects.” Publication FHWA/IN/JTRP-2004/07 Joint Transportation Research Program,West Lafayette, IN: Indiana Department of Transportation and Purdue University.

Flyvbjerg, B., Holm M. S., and Buhl, S. (2002). "Underestimating costs in public works projects. Error or lie?" J. Am. Plann. Assoc., 68(3), 279-296.

Flyvbjerg, B. (2006). "From Nobel Prize to Project Management: Getting Risks Right." Project Management Journal, 37 (3), pp. 5-15.

Grau, D., and Back, W.E. (2015). "Predictability Index - A Novel Metric to Assess Cost and Schedule Performance." ASCE, Journal of Construction Engineering and Management, 04015043-1 to -8.

Grau, D., and Cruz-Rios, F. (2019). Project Validation - A Guide to Improving Project Value and Team Performance. Version 1.0. School of Sustainable Engineering and the Built Environment, Ira A. Fulton Schools of Engineering, Arizona State University, Tempe, AZ, USA.

Grau, D., Back, E., Abbaszadegan, A., and Sirven, R. (2014). "The Predictability Index A Novel Project Performance Metric to Assess the Early Prediction of Cost and Time Outcomes." Conference Proceedings, Construction Research Congress 2014, pp. 2306-2314, Atlanta, GA, May 19 - 21, 2014.

Grau, D., Back, W.E., and Aguilar, G.M. (2017). "Organizational Behavior Influence on Predictability." ASCE, Journal of Management in Engineering, 33(5), pp. 04017027-1 to -8 .

Grau, D., Back, W.E., and Hossain, N. (2016). "Influence of Risk and Change Events on Cost, Schedule, and Predictability Performances." ASCE, Journal of Professional Issues in Engineering Education and Practice, 04016006-1 to -9.

Gummesson, E. (2000). Qualitative Methods in Management Research. 2nd ed. Thousand Oaks, Calif: Sage Publications. 
Hartley, Jean (1994). Case studies in organizational research. In Catherine Cassell \& Gillian Symon (Eds.), Qualitative methods in organizational research, a practical guide (pp.208-229). London: Sage.

Isidore, L.J., and Back, E. (2002). "Multiple simulation analysis for probabilistic cost and schedule integration." J. Constr. Eng. Manage., 128(3), 211-219.

Kim, B.C., and Reinschmidt, K.F. (2011). Combination of project cost forecasts in earned value management. Journal of Construction Engineering and Management, 137(11), 958-966.

Liu, Y., Hansen, M., Wang, Z., Gupta, G., and Malik, W. (2013). "Predictability in airport surface operation management." Aviation Technology, integration, and Operations Conference, Los Angeles, CA

McKenna, M.G., Wilcznski, H, and VanderSchee, D. (2006). "Capital project execution in the oil and gas industry: Increased challenges, increased opportunities." McLean, VA: Booz Allen Hamilton $\quad<$ Retrieved from http://www.boozallen.com/media/file/Capital_Project_Execution.pdf> (January 2019)

Mulva, S.P., and Dai, J. (2012). Performance assessment. Austin, TX: Construction Industry Institute and The University of Texas at Austin.

Oberlender, G. D., and Trost M. (2001). "Predicting accuracy of early cost estimates based on estimate quality." J. Constr. Eng. Manage., 127(3), 173-182.

Payne, J. H. (1995). "Management of multiple simultaneous projects: a state-of-the-art review." International Journal of Project Management, 13(3), 163-168.

R. Cheng, M. Allison, H. Ashcraft, S. Klawans, and J. Pease (2018). "Integrated Project Delivery -An Action Guide for Leaders." University of Washington, Seattle, WA, USA.

Welde, M., \& Odeck, J. (2017). "Cost escalations in the front-end of projects - empirical evidence from Norwegian road projects.” Transport Reviews, 37:5, 612-630.

Yin, R, K. (2014). Case study research: design and methods. Fifth Edition. Thousand Oaks,

Calif: Sage Publications. 